\title{
SEQUENTIAL EXTRACTION PROCEDURE: A VERSATILE TOOL FOR ENVIRONMENTAL RESEARCH
}

\author{
Maria Villen-Guzman *, Maria del Mar Cerrillo-Gonzalez, Juan M. Paz-Garcia, Carlos \\ Vereda-Alonso, Cesar Gomez-Lahoz and Jose M. Rodriguez-Maroto
}

Department of Chemical Engineering, Faculty of Sciences, University of Malaga, 29071, Malaga, Spain

Article Info:

Received:

1 June 2020

Revised:

31 July 2020

Accepted:

4 September 2020

Available online:

28 December 2020

Keywords:

Sequential Extraction Procedure

Metal recovery

Critical Raw Materials

Solid matrices

Circular economy
ABSTRACT

The sequential extraction procedure as a tool to assess the environmental risk of metals in solid matrices has been widely studied. In this work, another promising application of these methods is proposed: the evaluation of the recoverability of critical raw materials from a solid matrix. To this aim, the normalized sequential extraction procedure BCR was applied to a contaminated soil from the south of Spain. In addition to this, the influence of the incomplete dissolution of carbonates contained in the soil on the fractionation results has been also studied. The high percentage of metal in the most mobile fractions suggested the potential use of the solid matrix as secondary source. The use of this approach together with environmental and economic feasibility studies would be an approach toward the circular economy.

\section{INTRODUCTION}

The use of Sequential Extraction Procedures (SEPs) to assess toxic elements in a wide range of sample types has rapidly increased since their introduction in 1979. Tessier et al. (1979) presented the first influential SEPs based on a five-stage extraction to fractionate several metals ( $\mathrm{Cd}, \mathrm{Co}, \mathrm{Cu}, \mathrm{Fe}, \mathrm{Pb}, \mathrm{Mn}, \mathrm{Ni}$ and $\mathrm{Zn}$ ) in river sediments. This analytical procedure consists of the partitioning of particle trace metal into five fractions: exchangeable, bound to carbonates, bound to Fe-Mn oxides, bound to organic matter, and residual using appropriate reagents. The extraction steps intended to simulate real changes in environmental conditions affecting metal binding in freshwater sediments, such as acidification by rainwater, reduction because of the post-depositional burial in a sediment column and oxidation after dredging and land-deposition of anoxic sediments. Although SEPs were originally described for sediments, they were soon applied to soil considering the similarities between soils and sediments (Sutherland, 2010). The increasing use of SEPs in a variety of samples at different experimental conditions made the standardization of the procedure necessary. Hence, the Commission of the European Communities developed the protocol known as Community Bureau of Reference (BCR) consisting in a three-stage procedure to split the total metal into three fractions: exchangeable, reducible and oxidizable (Rauret et al., 2000). In addition to the aforementioned fractions, it was recommended to carry out an acid digestion of the solid residue from oxidation step to obtain the total metal in the solid sample. Since the development of the standardized protocol, a wide variety of samples, such as soil, sediment, mine spoil, sewage sludge, compost, incinerator ashes and electric furnace dust, has been analyzed following this approach (Bacon \& Davidson, 2008; Khadhar et al., 2020; Qureshi et al., 2020; Shehu et al., 2009).

It is widely accepted that the extensive use of SEPs entails wrong interpretation of results such as the association of metal fractions with specific mineral phases. Therefore, it is important to highlight that this procedure only divides the metal content into several fractions soluble in specific reagents under particular experimental conditions. Furthemore, some limitations of SEPs should be considered to properly interpret the experimental results. As a case in point, incomplete metal dissolution during the first step of the procedure for solid matrices with high concentration in carbonates entailing the overestimation of the next steps has been reported (Sulkowski \& Hirner, 2006). This fact has been related to the non-complete recovery of carbonate-bound metals and the influence of the increased $\mathrm{pH}$ value on the partitioning of elements in subsequent steps. Although some studies have proposed different approaches to avoid these interferences, researchers usually follow the standard method as described in the guidelines.

Regarding applications, the SEPs are one of the most promising tool for the risk assessment and the feasibili- 
ty studies of the remediation techniques. The most used approach is the "before and after" application of the protocol to obtain information about the changes in the contaminant mobility because of the applied treatment (Reddy et al., 2001; Yuan \& Weng, 2006). In some cases, these changes are even more important than the total amount of contaminant removed during the treatment (García-Rubio et al., 2011). Some studies reported the use of SEPs to predict the maximum amount of metal removable from the solid matrix (Subirés-Muñoz et al., 2011; Villen-Guzman et al., 2014, 2015). The evaluation of the time-dependence of contaminants in solid matrixes, named as "aging", has been also based on SEPs. In these studies, the incorporation of heavy metals from more mobile fractions into more stable fraction could be detected applying SEPs (Alexander, 2000; Jalali \& Khanlari, 2008; Villen-Guzman et al., 2018).

In this work, the use of a SEP to evaluate the recovery of Critical Raw Materials (CRMs) from solid matrixes is proposed. On this matter, the European Commission (EC) launched a directive in 2008 aiming, among other goals, at the identification of CRMs. After the assessment of 41 raw materials, 14 materials were identified as critical in 2011 (European Commission, 2011). The list of CRM is regularly updated to consider the market and technological development (European Commission, 2014, 2017a). The contrasting of two parameters (Economic Importance and Supply Risk) with established threshold values allows the evaluation of the criticality: Economic Importance (EI) in terms of end-use applications and the value added of corresponding European Union (EU) manufacturing sectors; and Supply Risk (SR) based on the concentration of primary supply from raw materials producing countries, considering their governance performance and trade data. Therefore, CRMs are both of high economic importance for the EU, i.e. relevant for industry sectors that create added value and jobs, and vulnerable to supply disruption since the supply is associated with high risk of not being adequate to meet EU industry demand (Blengini et al., 2017). The use of BCR protocol to assess the recovery of metals from two soils with a high carbonate content is presented in this work.

\section{EXPERIMENTAL}

\subsection{Soil collection}

The soil samples (S1 and S2) were collected at 10-30 $\mathrm{cm}$ from two different places of the mining district of Lin- ares, Spain (Figure 1). A detailed description of these soils has been previously presented (Villen-Guzman et al., 2018). In brief, the particle-size distribution indicated that soils S1 and S2 are classified as sand-loam and clay-loam soil, respectively, according to the International Soil Science Classification. Other relevant properties of these soils are a low organic matter content, an alkaline $\mathrm{pH}$, a medium-low cation exchange capacity, a low humidity, a large carbonate content and a very low hydraulic conductivity.

\subsubsection{Total metal concentration and carbonate content}

The total content of metals was determined following the EPA method 3051 A (Microwave assisted acid digestion of sediments, sludges, soils and oils): a solid sample of $100 \mathrm{mg}$ was extracted with $6 \mathrm{~mL}$ of concentrated nitric acid and $9 \mathrm{~mL}$ of concentrated hydrochloric acid for 10 minutes using microwave digestion. This procedure was carried out in triplicate to assure reproducible results. The metal concentration of aqueous solution was determined by Atomic Absorption (Varian SpectraAA-110). The carbonate content was obtained by thermogravimetry (TGA) together with differential scanning calorimetry analysis (DCS) (TA SDT Q600 instrument).

\subsubsection{Sequential extraction procedure}

The BCR protocol consists of three sequential steps to obtain different fractions of each metal contained in the solid with different mobility (Rauret et al., 2000). A solid sample of $1 \mathrm{~g}$ is first treated with $40 \mathrm{~mL}$ of acetic acid solution $0.11 \mathrm{M}$ by shaking for $16 \mathrm{~h}$ at $22^{\circ} \mathrm{C}$ to release the exchangeable and the acid-extractable metals known as the weak acid soluble (WAS) fraction. Then, the remaining solid phase is separated by centrifugation (Sigma 2-6) at $3000 \mathrm{~g}$ for $20 \mathrm{~min}$. To obtain the reducible fraction (RED), $40 \mathrm{~mL}$ of solution of hydroxylamine hydrochloride $0.5 \mathrm{M}$ is added to solubilize metals by shaking for $16 \mathrm{~h}$ at $22^{\circ} \mathrm{C}$. The remaining solid phase is separated by centrifugation at $3000 \mathrm{~g}$ for $20 \mathrm{~min}$. In the third sequential step, $10 \mathrm{~mL}$ of hydrogen peroxide acid-stabilized to $\mathrm{pH} \mathrm{2-3}$ is added to the residue and it is digested at room temperature for $1 \mathrm{~h}$ with occasional manual shaking. Then, the digestion is carried out at $85^{\circ} \mathrm{C}$ in a water-bath until the final volume is reduced to less than $3 \mathrm{~mL}$. After adding $10 \mathrm{~mL}$ of hydrogen peroxide, the same procedure is repeated until reducing the volume of liquid to about $1 \mathrm{~mL}$. The residue is treated with $50 \mathrm{~mL}$ of

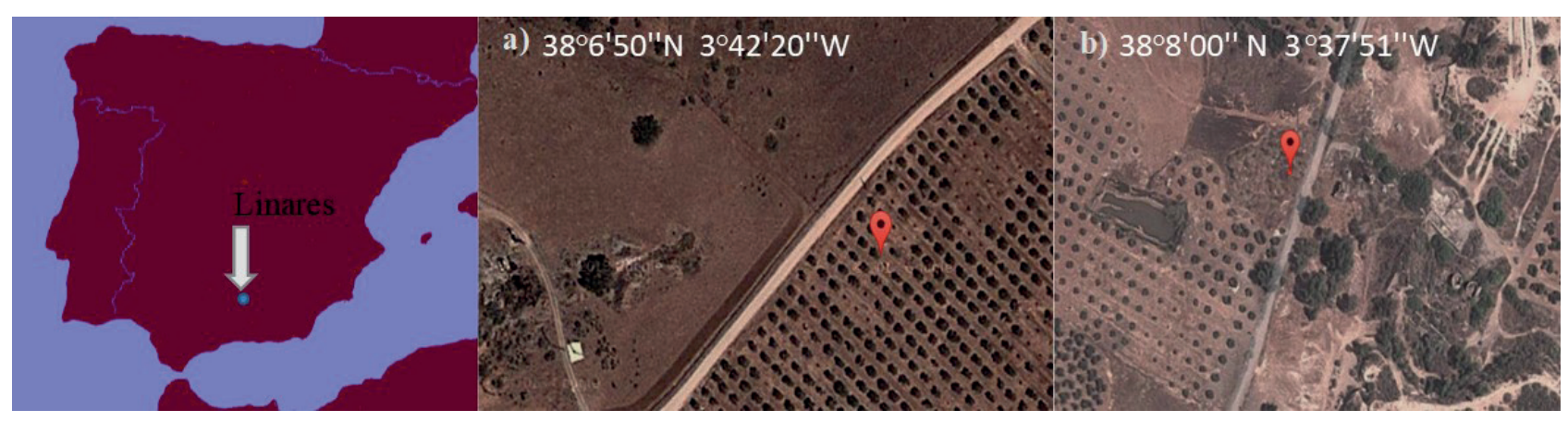

FIGURE 1: Sampling zone located at the south of Spain for soils: a) S1, b) S2. 
ammonium acetate $1 \mathrm{M}$ by shaking for $16 \mathrm{~h}$ at $22^{\circ} \mathrm{C}$ to obtain the oxidable fraction (OXI). The remaining solid phase is separated by centrifugation at $3000 \mathrm{~g}$ for $20 \mathrm{~min}$. As a final point, an acid digestion of the solid sample following the methodology presented in 2.2.1 is performed to obtain the residual content (RES) of metals in the soil. A modified version of the BCR method was performed to evaluate the influence of carbonate content on metal extraction during the first step of the SEP. To that end, the first step was repeated for 11 times and the $\mathrm{pH}$ of solution after extraction was monitored. With the aim of assuring reproducible results, the procedure was performed in triplicate.

\section{RESULTS AND DISCUSSION}

\subsection{Total metal concentration and carbonate content}

Figure 2 shows the total concentration of the most representative metals for the soil samples S1 and S2. The total concentration of metals under study was significantly higher in the soil sample S2. The most relevant metal was $\mathrm{Pb}$, which represents a serious environmental risk. The high concentration of $\mathrm{Pb}$ is due to the historical exploitation of galena ore $(\mathrm{PbS})$ in this region. In addition to $\mathrm{Pb}$, high concentrations of $\mathrm{Fe}$ and $\mathrm{Ca}, 37 \mathrm{~g} \mathrm{~kg}^{-1}$ and $34 \mathrm{~g} \mathrm{~kg}^{-1}$, respectively for soil S2 were reported.

Regarding the carbonate content, it was $37.25 \pm 8.00$ and $85.00 \pm 1.90 \mathrm{~g} \mathrm{~kg}^{-1}$ for S1 and S2 samples, respectively. As mentioned before, high concentration of carbonates could lead to incomplete metal dissolution during the acetic acid step, i.e. the first step of the BCR.

According to the European Commission, the metals contained in the soil to be assessed for its criticality were: $\mathrm{Pb}, \mathrm{Mn}, \mathrm{Cu}, \mathrm{Zn}$ and $\mathrm{Mg}$ (European Commission, 2017c). The values of the two parameters analyzed to evaluate the criticality of raw materials SR and El, for each metal are presented in Figure 3. The assessment methodology to calculate these parameters was revised in 2017 to include important improvements, such as: use of data from over the last 5 years instead of the last available year, introduction of data source priority for calculation and determination of the stage of material production (extraction or processing) with the highest supply risk for the EU (European Commission, 2017b). The SR represents the risk of a disruption in the EU supply of the material. This parameter is based on the concentration of primary supply from raw materials producing countries, considering their governance performance and trade aspects. It is calculated considering the stability of the producing countries, the extent to which a raw material could be substituted and the recycling input rate. The $\mathrm{El}$ is associated with the potential consequences of an inadequate supply of the raw materials. This parameter is calculated by considering the fraction of each material associated with industrial mega sectors at EU level and their gross value added. This parameter is corrected by the substitution index related to technical and cost performance of the substitutes for individual applications (Ferro \& Bonollo, 2019).

As observed, $\mathrm{Mg}$ is classed as critical since the metal exceeds the minimum SR and El criticality thresholds which are 1 and 2.8, respectively. These results are associated with the lack of dolomite and refined $\mathrm{Mg}$ production in the EU (European Commission, 2017c). Mn could be defined as a borderline case with a value for the parameter El exceeding the threshold and with a value of SR almost at the threshold. These results indicate that $\mathrm{Mn}$ should be carefully evaluated in a future EU assessment of CRMs. On the other hand, $\mathrm{Pb}, \mathrm{Zn}$ and $\mathrm{Cu}$ exceeds the established threshold for El. Nevertheless, the SR value, which is based on the concentration of primary supply from raw materials producing countries considering their governance performance and trade data, is far from the established limits. In other words, $\mathrm{Pb}, \mathrm{Zn}$ and $\mathrm{Cu}$ are far from being considered CRMs for the European Union.

\subsection{Sequential extraction procedure}

Based on previously discussed results, the soil sample $S 2$ was selected to perform further studies. The BCR results for $\mathrm{Pb}, \mathrm{Mn}, \mathrm{Cu}, \mathrm{Zn}, \mathrm{Ca}$ and $\mathrm{Mg}$ are presented in Figure 4. The metal obtained in the first step represents the most mobile fraction, namely Weak Acid Soluble (WAS); i.e. natural phenomena as rain can mobilize this metal fraction. $A$

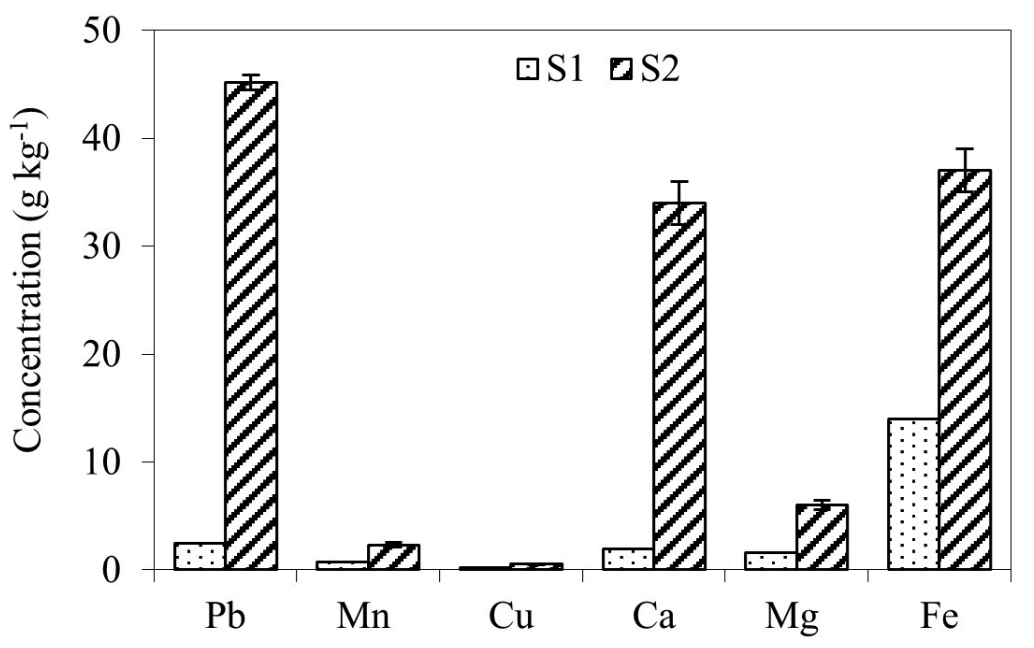

FIGURE 2: Total metal concentration in solid samples. 


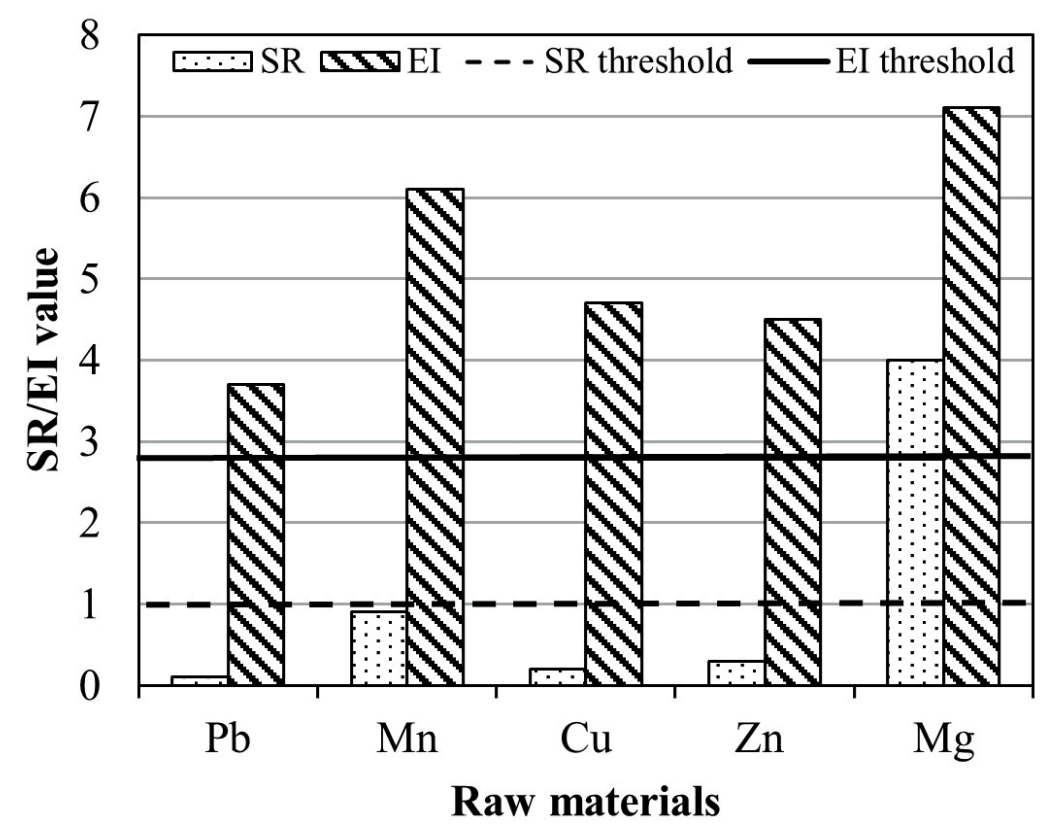

FIGURE 3: Criticality assessment results for $\mathrm{Mn}, \mathrm{Pb}, \mathrm{Cu}, \mathrm{Zn}$ and $\mathrm{Mg}$.

very high relative amount of $\mathrm{Pb}, 64 \%$, is contained as WAS fraction. These results indicate a potential environmental risk and put forward the need for soil remediation. On the other hand, the high concentration of metal in the most mobile fraction could be used to identify the solid sample as secondary source to obtain the metal. That is to say, the S2 soil sample could be an ideal raw material to obtain $\mathrm{Pb}$. The amount of $\mathrm{Ca}$ in the WAS fraction was almost $80 \%$ which has been associated with high concentrations of $\mathrm{CaCO}_{3}$. The amount of $\mathrm{Mg}$ contained as WAS fraction was $23 \%$. The reducible fraction (RED) is associated with the metal bounded to the Fe/Mn oxides. The most important relative amount of metal present in this fraction was found for $\mathrm{Mn}$ (58\%) and $\mathrm{Cu}(45 \%)$. The metal attached to organic matter and sulphides is present in the oxidable (OXI) fraction. The relative amount of metals present in this fraction was small with the higher values obtained for $\mathrm{Zn}(16 \%)$ and $\mathrm{Cu}(11 \%)$. Finally, the residual (RES) fraction provides a comparison of the results obtained in each step with the total metal content obtained from acid digestion. Except for Mg, no important percentages of metal were found in the less mobile fraction. The metal extracted in the residual fraction does not represent a risk for the environment due to its unavailability. That is to say, the $\mathrm{Mg}$ contained in this fraction could be classified as inaccessible. According to the results, $3 \mathrm{~g}$ $\mathrm{kg}^{-1}$ of $\mathrm{Mg}$ is found in the most mobile fractions (WAS and RED). The viability of using this soil sample as secondary source of $\mathrm{Mg}$ should be evaluated through economic and

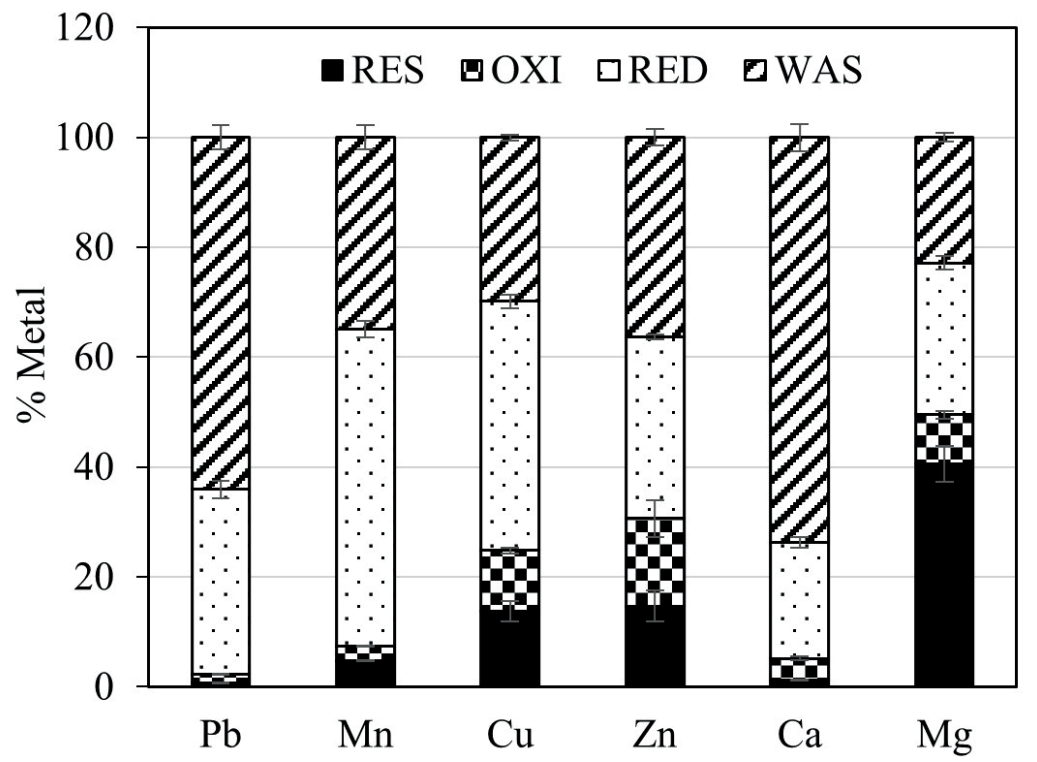

FIGURE 4: Sequential Extraction Procedure results of $\mathrm{Pb}, \mathrm{Mn}, \mathrm{Cu}$ and $\mathrm{Zn}$ for soil sample S2. 
environmental feasibility studies. Specifically, the extraction of $\mathrm{Mg}$ from this soil should be compared with conventional processes of $\mathrm{Mg}$ production from dolomite ore, such as the Pidgeon process. At this point, according to Du et al. (2010), the Pidgeon process has an intensive energy usage and generates a large amount of GHG emissions. Hence, the use of secondary raw materials is highly recommended to avoid problems associated not only with the criticality of $\mathrm{Mg}$ but also with the negative environmental impacts of conventional extraction methods.

With the aim of evaluating the influence of the high content of carbonates on BCR results, the first step (WAS) was repeated for 11 times before progressing to the next step (RES). The concentration of $\mathrm{Pb}$ has been selected to discuss these results due to its high concentration. Figure 5 shows the percentage of $\mathrm{Pb}$ in each fraction together with the $\mathrm{pH}$ value of the solution after each extraction step.

As can be observed, the dissolution efficiency has been enhanced by repeating the first extraction step. Results indicated that the WAS fraction would be underestimated about $34 \%$ following the normalized method. The monitoring of the $\mathrm{pH}$ value could be a useful approach to decide if it is needed to repeat the first extraction step before progressing to the next. The influence of the solid properties on BCR results should be considered not only in risk assessment studies but also in CRM recoverability studies through sequential extraction procedure.

\section{CONCLUSIONS}

The recoverability of metals from solid wastes has been properly assessed through the determination of total metal concentration together with the application of a sequential extraction procedure. According to the results, high percentage of metals in the most mobile fractions (WAS and RED) indicated not only a serious threat to the environment but also the possibility of using the solid matrix as secondary source of CRMs. The most environmentally relevant metal present in the soil, $\mathrm{Pb}$, has been previously categorized as economically important for the European Union. Therefore, the removal of $\mathrm{Pb}$ from the soil would entail not only the soil remediation but also the recovery of an important raw material. According to the $\mathrm{EU}, \mathrm{Mg}$ is the most relevant metal contained in the soil with a view to recovery. The low mobilizable concentration of this metal makes necessary to evaluate the economic and environmental feasibility of the recovery processes. The use of primary source of $\mathrm{Mg}$, such as dolomite ore, should be compared with the use of secondary source to promote circular economy. The procedure here presented offers promising results as a tool to be applied to different solid matrices and CRMs.

\section{AKNOWLED GEMENTS}

This work has received funding from the European Union's Horizon 2020 research and innovation programme under the Marie Skłodowska-Curie grant agreement No. 778045. The University of Malaga is acknowledged for the financial support in the postdoctoral fellowship of Villen-Guzman. Paz-Garcia acknowledges the financial support from the program "Proyectos I+D+i en el marco del Programa Operativo FEDER Andalucía 2014-2020”, No. UMA18-FEDERJA-279.

\section{REFERENCES}

Alexander, M. (2000). Aging, bioavailability, and overestimation of risk from environmental pollutants. Environmental Science \& Technology, 34(20), 4259-4265.

Bacon, J. R., \& Davidson, C. M. (2008). Is there a future for sequential chemical extraction? Analyst, 133(1), 25-46. https://doi. org/10.1039/B711896A.

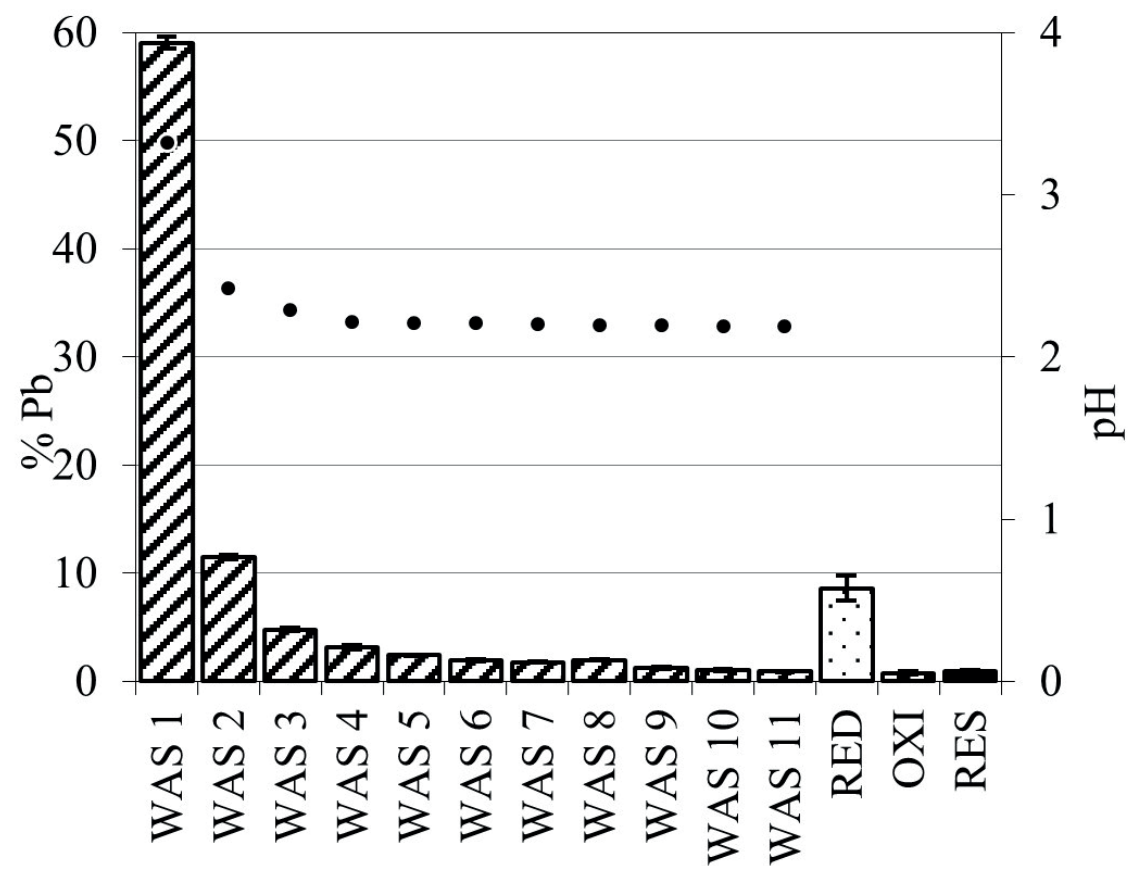

FIGURE 5: Sequential Extraction procedure of Pb for soil sample S2 repeating WAS step. 
Blengini, G. A., Blagoeva, D., Dewulf, J., Torres de Matos, C., Nita, V., Vidal-Legaz, B., Latunussa, C., Kayam, Y., Talens Peiró, L., Baranzelli, C. E. L., Manfredi, S., Mancini, L., Nuss, P., Marmier, A., Alves-Dias, P., Pavel, C., Tzimas, E., Mathieux, F., Pennington, D., \& Ciupagea, C. (2017). Assessment of the Methodology for Establishing the EU List of Critical Raw Materials.

Du, J., Han, W., \& Peng, Y. (2010). Life cycle greenhouse gases, energy and cost assessment of automobiles using magnesium from Chinese Pidgeon process. Journal of Cleaner Production, 18(2), 112-119. https://doi.org/10.1016/j.jclepro.2009.08.013

European Commission. (2011). Communication from the commission to the European Parliament, the Council, the European Economic and Social Committee and the Committee of the regions: Tackling the challenges in commodity markets and on raw materials. (COM (2011) 25 final).

European Commission. (2014). Communication from the commission to the European Parliament, the Council, the European Economic and Social Committee and the Committee of the regions: On the review of the list of critical raw materials for the $\mathrm{EU}$ and the implementation of the Raw Materials Initiative (COM (2014) 297 final).

European Commission. (2017a). Communication from the commission to the European Parliament, the Council, the European Economic and Social Committee and the Committee of the regions on the 2017 list of Critical Raw Materials for the EU (COM (2017) 40 final).

European Commission. (2017b). Methodology for establishing the EU list of Critical Raw Materials: Guidelines.

European Commission. (2017c). Study on the review of the list of Critical Raw Materials. Criticality Assessments.

Ferro, P., \& Bonollo, F. (2019). Materials selection in a critical raw materials perspective. Materials \& Design, 177, 107848. https://doi. org/10.1016/j.matdes.2019.107848

García-Rubio, A., Rodríguez-Maroto, J. M., Gómez-Lahoz, C., García-Herruzo, F., \& Vereda-Alonso, C. (2011). Electrokinetic remediation: The use of mercury speciation for feasibility studies applied to a contaminated soil from Almadén. Electrochimica Acta, 56(25), 9303-9310.

Jalali, M., \& Khanlari, Z. V. (2008). Effect of aging process on the fractionation of heavy metals in some calcareous soils of Iran. Geoderma, 143(1), 26-40.

Khadhar, S., Sdiri, A., Chekirben, A., Azouzi, R., \& Charef, A. (2020). Integration of sequential extraction, chemical analysis and statistical tools for the availability risk assessment of heavy metals in sludge amended soils. Environmental Pollution, 263, 114543. https://doi. org/10.1016/j.envpol.2020.114543

Qureshi, A. A., Kazi, T. G., Baig, J. A., Arain, M. B., \& Afridi, H. I. (2020). Exposure of heavy metals in coal gangue soil, in and outside the mining area using BCR conventional and vortex assisted and single step extraction methods. Impact on orchard grass. Chemosphere, 255, 126960. https://doi.org/10.1016/j. chemosphere.2020.126960
Rauret, G., Lopez-Sanchez, J.-F., Sahuquillo, A., Barahona, E., Lachica, M., Ure, A. M., Davidson, C. M., Gomez, A., Luck, D., Bacon, J., Yli-Halla, M., Muntau, H., \& Quevauviller, Ph. (2000). Application of a modified BCR sequential extraction (three-step) procedure for the determination of extractable trace metal contents in a sewage sludge amended soil reference material (CRM 483), complemented by a three-year stability study of acetic acid and EDTA extractable metal content. Journal of Environmental Monitoring, 2(3), 228-233.

Reddy, K. R., Xu, C. Y., \& Chinthamreddy, S. (2001). Assessment of electrokinetic removal of heavy metals from soils by sequential extraction analysis. Journal of Hazardous Materials, 84(2), 279-296. https://doi.org/10.1016/S0304-3894(01)00237-0

Shehu, A., Lazo, P., \& Pjeshkazini, L. (2009). Evaluation of metal species in sediment, using the BCR sequential and single extraction. Journal of Environmental Protection and Ecology, 10(2), 386-393.

Subirés-Muñoz, J. D., García-Rubio, A., Vereda-Alonso, C., Gómez-Lahoz, C., Rodríguez-Maroto, J. M., García-Herruzo, F., \& Paz-García, J. M. (2011). Feasibility study of the use of different extractant agents in the remediation of a mercury contaminated soil from Almaden. Separation and Purification Technology, 79(2), 151-156.

Sulkowski, M., \& Hirner, A. V. (2006). Element fractionation by sequential extraction in a soil with high carbonate content. Applied Geochemistry, 21(1), 16-28. https://doi.org/10.1016/j.apgeochem.2005.09.016

Sutherland, R. A. (2010). BCR $B-701$ : A review of 10-years of sequential extraction analyses. Analytica Chimica Acta, 680(1-2), 10-20. https://doi.org/10.1016/j.aca.2010.09.016

Tessier, A., Campbell, P. G. C., \& Blsson, M. (1979). Sequential extraction procedure for the speciation of particulate trace metals. Analytical Chemistry, 51(7), 844-851.

Villen-Guzman, M., Garcia-Rubio, A., Paz-Garcia, J. M., Vereda-Alonso, C., Gomez-Lahoz, C., \& Rodriguez-Maroto, J. M. (2018). Aging effects on the mobility of $\mathrm{Pb}$ in soil: Influence on the energy requirements in electroremediation. Chemosphere, 213, 351-357. https://doi.org/10.1016/j.chemosphere.2018.09.039

Villen-Guzman, M., Paz-Garcia, J. M., Rodriguez-Maroto, J. M., Garcia-Herruzo, F., Amaya-Santos, G., Gomez-Lahoz, C., \& Vereda-Alonso, C. (2015). Scaling-up the acid-enhanced electrokinetic remediation of a real contaminated soil. Electrochimica Acta, 181, 139-145. https://doi.org/10.1016/j.electacta.2015.02.067

Villen-Guzman, M., Paz-Garcia, J. M., Rodriguez-Maroto, J. M., Gomez-Lahoz, C., \& Garcia-Herruzo, F. (2014). Acid Enhanced Electrokinetic Remediation of a Contaminated Soil using Constant Current Density: Strong vs. Weak Acid. Separation Science and Technology, 49(10), 1461-1468. https://doi.org/10.1080/014963 95.2014.898306

Yuan, C., \& Weng, C.-H. (2006). Electrokinetic enhancement removal of heavy metals from industrial wastewater sludge. Chemosphere, 65(1), 88-96. https://doi.org/10.1016/j.chemosphere.2006.02.050 